\title{
Electroconvulsive Therapy and Oxidative Stress: Comment on the Article of Şenyurt et al. (Clin Psychophacol Neurosci 2017;15:40-46)
}

\author{
Tevfik Kalelioglu ${ }^{1}$, Abdullah Genc ${ }^{2}$, Nesrin Karamustafalioglu ${ }^{1}$ \\ ${ }^{1}$ Department of Psychiatry, Bakırköy Mental Health Research and Teaching Hospital, ${ }^{2}$ Department of Psychiatry, Sisli Hamidiye Etfal Research \\ and Teaching Hospital, Istanbul, Turkey
}

\section{TO THE EDITOR}

We recently read with interest the article by Şenyurt et al. titled "Evaluation of Oxidative Status in Patients Treated with Electroconvulsive Therapy" published in February 2017 in this journal. ${ }^{1)}$ The authors conducted a study suggesting that electroconvulsive therapy (ECT) has no negative effect on oxidative stress in terms of serum total oxidant status (TOS), total antioxidant status (TAS) and their ratio oxidative stress index (OSI). Even though the sub-groups have small sample size which may be inadequate for a statistically significance, they found that OSI levels were decreased significantly in schizophrenia, insignificantly in bipolar and major depressive groups after ECT when compared with pre-ECT levels. ${ }^{1)}$

We would like to comment on this research. Despite the fact that this study has negative trial results which is also negative factor for publishing, we believe that it contributes valuable information as important as positive results in the growing evidence of the relation between ECT and oxidative stress. There are a limited number of clinical studies about effect of ECT on oxidative mechanisms. ${ }^{2-4)}$ Besides evaluating the oxidant-antioxidant molecules individually, evaluating the total oxidant and antioxidant capacity may have a potential to reflect the status of whole system homeostasis. Hence, we think that this study has an advantage to reflect such an association between ECT and oxidative homeostasis.

Antipsychotics are important therapeutic agents used in treatment of schizophrenia, bipolar disorder and also major depressive disorder. The authors state that the anti-

Received: February 13, 2017 / Accepted: February 21, 2017

Address for correspondence: Tevfik Kalelioglu, MD

Department of Psychiatry, Bakırköy Mental Health Research and

Teaching Hospital, Zuhuratbaba mah. 34147 Bakirköy, Istanbul,

Turkey

Tel: +90-212-543-6565, Fax: +90-212-409-1595

E-mail: tevfikkaleli@hotmail.com psychotics have positive effects on oxidative stress. However, on contrary, preclinical and in-vitro studies demonstrate increased oxidative stress particularly with typical antipsychotics. ${ }^{5-7)}$ Furthermore, in our previously published study, we evaluated serum TAS, TOS and OSI levels in manic state and alterations with the treatment modalities of ECT + antipsychotics or antipsychotics alone. Strikingly we have found that only antipsychotic group showed a significant increase in OSI levels whereas no significant change was observed in ECT + antipsychotic group in terms of oxidative stress. As similar to abovementioned studies, clinically we demonstrated that antipsychotics might increase oxidative burden. ${ }^{8)}$

Taken together, in concordance with the current study performed by Şenyurt et al., ${ }^{1)}$ our previous study has indicated that ECT may have positive or at least no additional influences on oxidative stress. Studies with larger samples and refined groups from effect of confounders are required to confirm these findings.

\section{REFERENCES}

1. Şenyurt M, Aybek H, Herken H, Kaptanoglu B, Korkmaz A. Evaluation of oxidative status in patients treated with electroconvulsive therapy. Clin Psychopharmacol Neurosci 2017; 15:40-46.

2. Genc A, Kalelioglu T, Karamustafalioglu N, Tasdemir A, Gungor FC, Genc ES, et al. Level of plasma thioredoxin in male patients with manic episode at initial and post -electroconvulsive or antipsychotic treatment. Psychiatry Clin Neurosci 2015;69:344-350.

3. Jorgensen A, Krogh J, Miskowiak K, Bolwig TG, Kessing LV, Fink-Jensen A, et al. Systemic oxidatively generated $D N A / R N A$ damage in clinical depression: associations to symptom severity and response to electroconvulsive therapy. $J$ Affect Disord 2013;149:355-362.

4. Kartalci S, Karabulut AB, Ozcan AC, Porgali E, Unal S. Acute and chronic effects of electroconvulsive treatment on oxidative parameters in schizophrenia patients. Prog Neuropsychopharmacol Biol Psychiatry 2011;35:1689-1694.

5. Abdel-Sattar EA, Mouneir SM, Asaad GF, Abdallah HM. Protective effect of Calligonum comosum on haloperidol-

(a) This is an Open-Access article distributed under the terms of the Creative Commons Attribution Non-Commercial License (http://creativecommons.org/licenses/by-nc/4.0) which permits unrestricted non-commercial use, distribution, and reproduction in any medium, provided the original work is properly cited. 
induced oxidative stress in rat. Toxicol Ind Health 2014;30: 147-153.

6. Dietrich-Muszalska A, Kontek B, Rabe-Jabłońska J. Quetiapine, olanzapine and haloperidol affect human plasma lipid peroxidation in vitro. Neuropsychobiology 2011;63:197-201.

7. Raudenska M, Gumulec J, Babula P, Stracina T, Sztalmachova $\mathrm{M}$, Polanska $\mathrm{H}$, et al. Haloperidol cytotoxicity and its relation to oxidative stress. Mini Rev Med Chem 2013;13: 1993-1998.

8. Kalelioglu T, Genc A, Karamustafalioglu N, Tasdemir A, Can Gungor F, Cansiz A, et al. Initial and post-treatment total oxidant-antioxidant status and oxidative stress index in male patients with manic episode. Psychiatry Res 2014; 218:249-251. 